\title{
Metabolic Responses to High-Fat or Low-Fat Meals and Association with Sympathetic Nervous System Activity in Healthy Young Men
}

\author{
Narumi NAGAI ${ }^{1,2}$, Naoki SAKANE ${ }^{3}$ and Toshio MORITANI ${ }^{1, *}$ \\ ${ }^{1}$ Laboratory of Applied Physiology, Graduate School of Human and Environmental Studies, \\ Kyoto University, Sakyo-ku, Kyoto 606-8501, Japan \\ ${ }^{2}$ Department of Nutritional Science, Faculty of Health and Welfare, Okayama \\ Prefectural University, Okayama 719-1197, Japan \\ ${ }^{3}$ Department of Preventive Medicine, Clinical Research Institute, Center for Endocrine and \\ Metabolic Disease, National Hospital Organization Kyoto Medical Center, Kyoto 612-8555, Japan
}

(Received February 9, 2005).

\begin{abstract}
Summary The present study was designed to investigate the metabolic and sympathetic responses to a high-fat meal in humans. Fourteen young men (age: $23.6 \pm 0.5 \mathrm{y}$, BMI: $21.3 \pm 0.4 \mathrm{~kg} / \mathrm{m}^{2}$ ) were examined for energy expenditure and fat oxidation measured by indirect calorimetry for $3.5 \mathrm{~h}$ after a high-fat (70\% energy from fat) or an isoenergetic lowfat $(20 \%$ energy from fat) meal served in random order. The sympathetic nervous system (SNS) activity was assessed using power spectral analysis of heart rate variability (HRV). After the high-fat meal, increases in thermoregulatory SNS activity (very low-frequency component of HRV, $0.007-0.035 \mathrm{~Hz}, 577.4 \pm 45.9$ vs. $\left.432.0 \pm 49.3 \mathrm{~ms}^{2}, p<0.05\right)$ and fat oxidation $(21.0 \pm 5.3$ vs. $13.3 \pm 4.3 \mathrm{~g}, p<0.001)$ were greater than those after the low-fat meal. However, thermic effects of the meal (TEM) were lower after the high-fat meal than after the low-fat meal $(27.5 \pm 11.2$ vs. $36.1 \pm 10.9 \mathrm{kcal}, p<0.05)$. In conclusion, the highfat meal can stimulate thermoregulatory SNS and lipolysis, but resulted in lower TEM, suggesting that a high proportion of dietary fat intake, even with a normal daily range of calories, may be a potent risk factor for further weight gain.
\end{abstract}

Key Words thermic effect of meal, sympathetic nervous system, power spectral analysis, heart rate variability, fat oxidation

In rodents, high-fat meals increase the thermic effects of the meal (TEM) (1) as well as uncoupling protein 1 (UCP1) gene expression (2) in brown adipose tissue (BAT) through norepinephrine secretion from sympathetic nerve endings. Additionally, some studies have shown direct effects of plasma fatty acid concentrations on excitation of the sympathetic nervous system (SNS) in rats (3) and humans (4).

Since the SNS modulates the facultative thermogenesis including the TEM, a sympathetic withdrawal can make energy balance regulation more vulnerable (5). Although accentuations of sympathetic as well as thermogenic responses to fat-intake or lipid-ingestion have been clarified in animal studies (1-3), they remain unclear in human studies. Some human studies have demonstrated that, despite activation of the SNS, a lower TEM is generally observed following a high-fat meal compared with a high-carbohydrate meal (6-8). Consequently, excess fat intake has been considered to lead to a positive energy balance over a short period (6). However, the reason for such inconsistent results has not been clarified.

Because a large number of studies using pharmacological agents have verified that the autonomic nervous

* To whom correspondence should be addressed.

E-mail: t.moritani@neuro.mbox.media.kyoto-u.ac.jp system (ANS) modulates the TEM in humans (5), assessing the ANS activity following meals with various fat contents may help to explain the association of the ANS and the TEM. The spectral analysis of heart rate variability (HRV) can evaluate the net effect of sympathetic (SNS) and parasympathetic nervous system (PNS) activity (9-11). Moreover, we previously found that complete autonomic blockade caused the abolition of heart rate fluctuations as well as a marked reduction in energy expenditure $(12,13)$. As for neural thermoregulation, we identified the very low-frequency component of the spectrum (VLF) reflecting the SNS activity including the function of thermogenic regulation in our previous experiments (12-16). We therefore feel confident that HRV spectral analysis is a safe and useful tool to assess both neurogenic and metabolic responses following the meals.

Accordingly, the present study examined the metabolic and sympathetic responses to high-fat and low-fat meals in humans in order to determine whether a highfat meal, even within a normal range of calories, can become a potential risk factor responsible for the development of obesity.

\section{METHODS}

Subjects. Young male volunteers aged 22-28 y $(n=14)$ were recruited from our campus. The profiles of 
the subjects are presented in Table 1. All subjects were non-smokers, healthy, free of disease, and not taking any medication that affected body composition or energy expenditure. The subjects provided written informed consent, and the study protocol was approved by the Institutional Ethical Committee of Kyoto University Graduate School.

Experimental procedure. On the day before the test, all consumption of food and drink had to cease before $2200 \mathrm{~h}$. The consumption of coffee, tea, and alcohol was prohibited on the day before the test, and no sports activities were permitted that evening.

On the day of the test, each subject arrived at the laboratory at $0730 \mathrm{~h}$ in a fasting condition. After measurement of height, body mass and percentage of body fat determined using a bioelectrical impedance analyzer (Model TBF-534, Tanita Corp, Tokyo, Japan), the subject was prepared with electrocardiogram (ECG) electrodes and then rested for at least $30 \mathrm{~min}$ in a temperature-controlled $\left(24-25^{\circ} \mathrm{C}\right)$ environment. After the subject had adjusted his respiratory mask, $\mathrm{CM}_{5}$ lead ECG and gas exchange parameters, were recorded using an open-circuit computerized indirect calorimeter (Aero monitor AE 280, Minato Medical Science, Tokyo, Japan) while the subject remained seated in a comfortable chair. The calorimeter was calibrated before each test with a reference gas mixture $\left(15 \% \mathrm{O}_{2}\right.$ and $\left.5 \% \mathrm{CO}_{2}\right)$. Continuous ventilatory volumes, $\dot{\mathrm{V}} \mathrm{O}_{2}$ and $\dot{\mathrm{V}} \mathrm{CO}_{2}$, were displayed on a computer at $15 \mathrm{~s}$ intervals and the mean value for each minute was printed out.

The test meal was served at $0830 \mathrm{~h}$ and eaten within $15 \mathrm{~min}$. Postprandial energy expenditure (EE) was measured for $210 \mathrm{~min}$ (until $1200 \mathrm{~h}$ ), and ECG and gas samples were taken every $30 \mathrm{~min}$ for a period of $6 \mathrm{~min}$. During the test period, the subjects remained seated.
Diet. The energy content of the meal corresponded to one third of each subject's daily energy requirement, determined using reference values from metabolism tables for Japanese (17). A multiplication factor of 1.5 was used to account for the medium physical activity level of the subjects. The low-fat meal ( $70 \%$ of energy as carbohydrate, $20 \%$ as fat, and $10 \%$ as protein) and high-fat meal ( $20 \%$ of energy as carbohydrate, $70 \%$ as

Table 1. Physical characteristics and the parameters of energy metabolism during pre and postprandial periods of subjects $(n=14)$.

$\begin{array}{lc}\text { Age }(\mathrm{y}) & 23.6(0.5) \\ \text { Height }(\mathrm{cm}) & 174(2.2) \\ \text { Body mass }(\mathrm{kg}) & 64.8(1.7) \\ \text { BMI }\left(\mathrm{kg} / \mathrm{m}^{2}\right) & 21.3(0.4) \\ \text { Body fat }(\%) & 18.4(1.0) \\ \text { Nutritional requirement }(\mathrm{kJ} / \mathrm{d}) & 9,763(253) \\ \text { Test meal energy }(\mathrm{kJ}) & 3,255(85) \\ \text { Low-fat meal } & \\ \text { Preprandial EE }(\mathrm{kJ} / \mathrm{d}) & 9,007(263) \\ \text { TEM }(\mathrm{kJ} / 3.5 \mathrm{~h}) & 151(13.3) \\ \text { TEM }(\% \text { preprandial EE) } & 1.7(0.2) \\ \text { TEM (\% energy intake) } & 4.7(0.4) \\ \text { High-fat meal } & \\ \text { Preprandial EE (kJ/d) } & 11957(292) \\ \text { TEM (kJ/3.5 h) } & 1.3(0.1)^{*} \\ \text { TEM (\% preprandial EE) } & 3.6(0.4)^{*} \\ \text { TEM (\% energy intake) } & \\ \text { Values represent means (SE). Nutritional requirements } \\ \text { were recommended by the Ministry of Health, Labor, and } \\ \text { Welfare of Japan. EE, energy expenditure. TEM, thermic } \\ \text { effect of meal. * } p<0.05, \text { low-fat vs. high-fat meal, by } \\ \text { paired } t \text {-test. }\end{array}$

Table 2. Composition, energy content, and macronutrient composition of the test meals. ${ }^{1}$

\begin{tabular}{|c|c|c|c|c|c|}
\hline Test meals & $\begin{array}{l}\text { Weight } \\
\text { (g) }\end{array}$ & $\begin{array}{l}\text { Energy } \\
(\mathrm{kJ})\end{array}$ & $\begin{array}{l}\text { Protein } \\
\text { (g) }\end{array}$ & $\begin{array}{l}\text { Fat } \\
(\mathrm{g})\end{array}$ & $\begin{array}{c}\text { Carbohydrate } \\
\text { (g) }\end{array}$ \\
\hline \multicolumn{6}{|l|}{ Low-fat meal } \\
\hline Boiled rice & 290 & 1,719 & 6.5 & 0.6 & 92.4 \\
\hline Vegetable stew & 195 & 867 & 8.0 & 14.2 & 14.5 \\
\hline Egg & 25 & 161 & 3.2 & 2.6 & 0.1 \\
\hline Margarine & 1 & 26 & 0 & 0.7 & 0 \\
\hline Low-fat yogurt & 50 & 140 & 1.2 & 0 & 8.0 \\
\hline Orange juice & 200 & 343 & 0 & 0.1 & 21.2 \\
\hline \multirow[t]{2}{*}{ Total } & 761 & 3,256 & 18.9 & 18.2 & 136.2 \\
\hline & & en\%: & 9.7 & 21.0 & 69.3 \\
\hline \multicolumn{6}{|l|}{ High-fat meal } \\
\hline Hamburger & 145 & 1,913 & 15.5 & 28.9 & 33.8 \\
\hline Egg & 25 & 161 & 3.3 & 2.6 & 0.1 \\
\hline Butter fat & 5 & 154 & 0.5 & 4.0 & 0 \\
\hline High-fat cream & 70 & 1,008 & 1.0 & 25.1 & 1.8 \\
\hline Sugar & 2 & 19 & 0 & 0 & 1.9 \\
\hline Water & 200 & 0 & 0 & 0 & 0 \\
\hline \multirow[t]{2}{*}{ Total } & 447 & 3,255 & 20.3 & 60.6 & 37.6 \\
\hline & & en $\%$ : & 10.4 & 70.3 & 19.3 \\
\hline
\end{tabular}

${ }^{1}$ Subjects were fed in energy balance, with a 10:70:20 ratio of protein/carbohydrate/fat and a $10: 20: 70$ percentage of energy, with individually fixed $50 \mathrm{~kJ}$ per kilogram of body mass. 
fat, and $10 \%$ as protein) were compiled using normal foods consumed for breakfast, and the intake was individualized according to the subject's age and body mass (Table 1). The macronutrient composition of the meals (Table 2) was calculated using the Japanese food composition table (18). Since our previous studies $(14,15)$ demonstrated that capsaicin and spice-containing meals can increase postprandial SNS activity, a smaller amount of spices (less than $0.5 \mathrm{~g}$ ) and no capsaicin were contained in the present test meals. Moreover, it should be noted that the difference in the palatability was not found between the two test meals because all subjects answered similarly 'palatable' in the questionnaires regarding food preference when they were fed each test meal.

Calculation of energy expenditure. The mean of a stable $12 \mathrm{~min}$ period was calculated for preprandial EE. The 7 periods of $6 \mathrm{~min}$ were averaged over the total $3.5 \mathrm{~h}$ thermogenic response. The respiratory quotient (RQ) was determined from $\dot{V} \mathrm{O}_{2}$ and $\dot{\mathrm{V}} \mathrm{CO}_{2}$. The EE, carbohydrate, and fat oxidation rates were calculated using the table of Lusk (19). The TEM was calculated by subtracting the preprandial EE value $\left(\mathrm{kJ} \cdot \mathrm{min}^{-1}\right)$ from the averaged postprandial $\mathrm{EE}\left(\mathrm{kJ} \cdot \mathrm{min}^{-1}\right)$, and this was multiplied by the duration of the postprandial period (210 min). The TEM was expressed as an absolute as well as relative values and a percentage increase over the preprandial EE

$R-R$ spectral analysis procedure. Our $\mathrm{R}-\mathrm{R}$ interval power spectral analysis procedures have been fully described elsewhere (10-16). Briefly, the ECG data obtained from the $\mathrm{CM}_{5}$ lead was digitized via a 13-bit analog-to-digital converter (HTB 410; Trans Era, Utah, USA) at a sampling rate of $1,024 \mathrm{~Hz}$. Then, the digitized $\mathrm{R}-\mathrm{R}$ interval time series was aligned in $2 \mathrm{~Hz}$ sequence (20) for power spectral analysis. The direct current component and linear trend were eliminated by digital filtering for the band-pass between 0.007 and $0.5 \mathrm{~Hz}$. The high-pass filtering at $0.007 \mathrm{~Hz}$ was chosen to include the frequency components associated with the

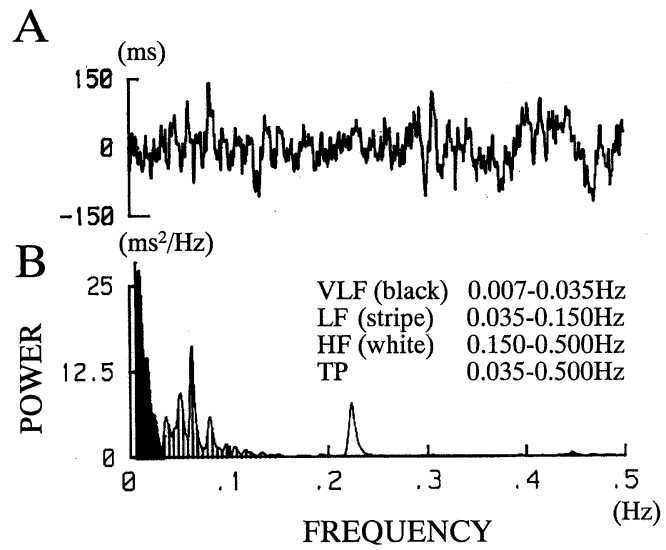

Fig. 1. A typical set of computer-aided ECG R-R interval power spectral analysis results: raw $R-R$ interval changes (A) and the corresponding power spectrum (B), from which various ANS activity components were derived (10-16). thermogenic function of the ANS (12-16). After passing through a Hamming-type data window, power spectral analysis using a fast Fourier transform was performed on a consecutive 1,024-s time series of R-R interval data obtained during the test.

To evaluate the ANS activity, we analyzed the very low frequency component (0.007-0.035 Hz, VLF), reflecting SNS activity related to energy metabolic regulation (12-14); low frequency component (0.035$0.15 \mathrm{~Hz}, \mathrm{LF})$, jointly regulated by both SNS and PNS activity; high frequency component $(0.15-0.5 \mathrm{~Hz}, \mathrm{HF})$, solely reflecting vagal activity; and total power $(\mathrm{LF}+\mathrm{HF}$, $0.035-0.5 \mathrm{~Hz}, \mathrm{TP})$, representing the overall ANS activity, by integrating the spectrum for the respective band width. Typical sets of raw R-R intervals (top) and the corresponding power spectrum (bottom) are illustrated in Fig. 1. During the resting and postprandial periods, the subject was requested to breathe in synchrony with a metronome 15 times $\cdot \mathrm{min}^{-1}(0.25 \mathrm{~Hz})$ to ensure that respiratory-linked variations in the heart rate did not overlap with LF components $(<0.15 \mathrm{~Hz})$ from other sources.

Statistical analyses. All data are presented as the mean \pm SE. All of the statistical analyses were performed with the Statistical Package for Social Science (SPSS for Windows, version 11.5, Inc., Chicago, IL). Statistical differences among the groups in terms of time course changes in the postprandial energy expenditure and SNS responses were analyzed by means of a two-way analysis of variance (ANOVA) with repeated measurements. All other group comparisons were made using Student's $t$-test. $p$ values $<0.05$ were regarded as significant.

\section{RESULTS}

\section{Metabolic response}

Meal-induced energy expenditure. Table 1 summarizes the physical characteristics and the parameters of

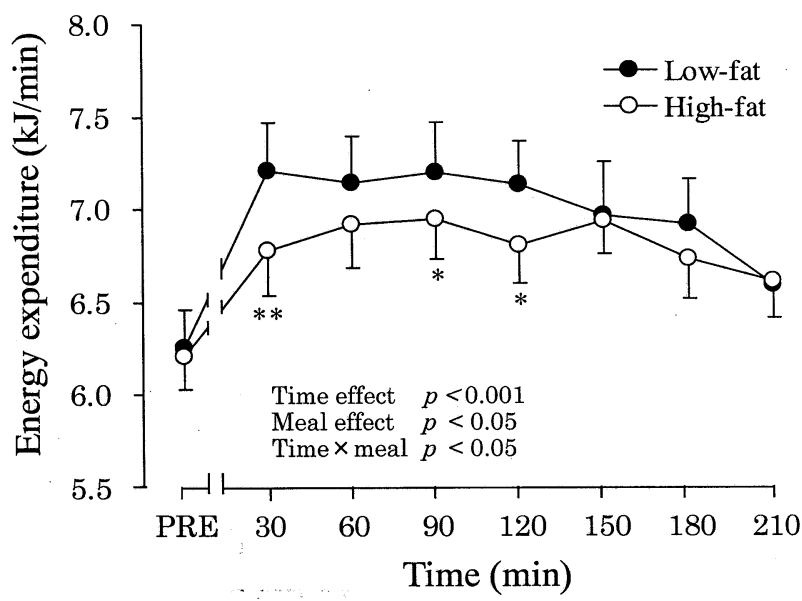

Fig. 2. Time course of pre- and postprandial energy expenditure (low-fat: $\bullet$, high-fat meal: $\bigcirc$ ). The results are expressed as the mean $\pm \mathrm{SE}$ for each meal. ${ }^{* *} p<0.01, * p<0.05$, low-fat vs. high-fat meal. Time effect, meal effect, and time $\times$ meal interaction were calculated by repeated ANOVA. 
energy metabolism during pre and postprandial periods for the subjects. As expected, there was no significant difference in the preprandial $\mathrm{EE}$ values of each test meal. Postprandial thermogenesis, expressed as TEM values, was significantly lower $(p<0.05)$ after the highfat meal than after the low-fat meal regardless of the expression, i.e., absolute or relative values (see Table 1).

Figure 2 shows the time course changes in EE before and after the low-fat and high-fat meals, expressed as absolute EE values of each test meal. The net increase in postprandial energy expenditure was significantly lower after the high-fat meal than after the low-fat meal (time $\times$ meal interaction, $F=2.8, p<0.05$ ).

Fat oxidation. Figure 3 shows the time course changes in the respiratory quotients $(\mathrm{RQ})$ after the lowfat and high-fat meals. RQ values were significantly lower after the high-fat meal than after the low-fat meal (time $\times$ meal interaction, $F=10.7, p<0.001$ ). The high-

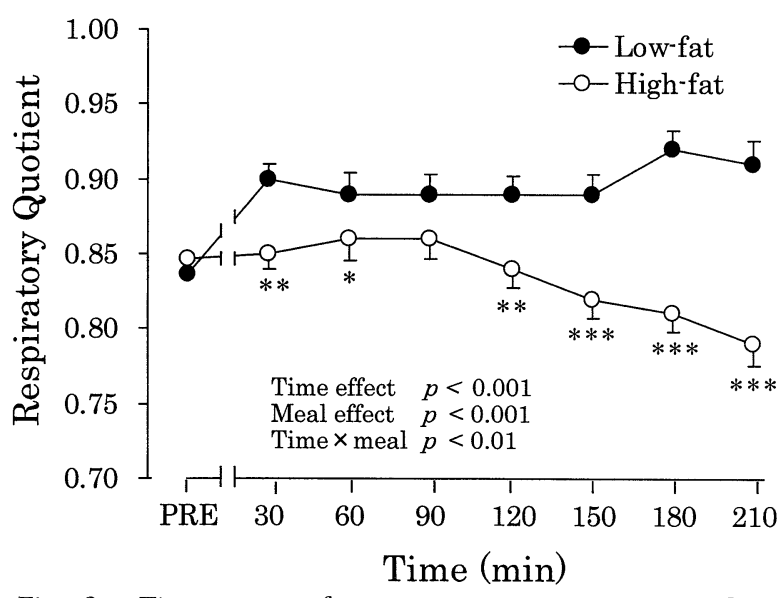

Fig. 3. Time course of respiratory quotient measured in preprandial conditions and after a test meal (low-fat: - high-fat meal: 0 ), ${ }^{* * *} p<0.001,{ }^{* *} p<0.01$, ${ }^{*} p<0.05$, low-fat vs. high-fat meal. Time effect, meal effect, and time $\times$ meal interaction were calculated by repeated ANOVA. fat meal produced a significantly higher increase in fat oxidation than the low-fat meal $(21.0 \pm 5.3$ vs. $13.3 \pm$ $4.3 \mathrm{~g}, p<0.001)$. Nevertheless, postprandial fat storage (fat intake-fat oxidation) was 10-fold higher (39.5 9.4 vs. $4.0 \pm 5.2 \mathrm{~g}, p<0.001)$ after the high-fat meal than after the low-fat meal.

Sympathetic nervous system response

Figure 4 shows the postprandial VLF (mean values) and the TEM after the low-fat and high-fat meals, respectively. The mean values of postprandial VLF, an index of thermoregulatory SNS activity (577.4 \pm 45.9 vs. $\left.432.0 \pm 49.3 \mathrm{~ms}^{2} ; \quad p<0.05\right)$ were significantly greater after the high-fat meal than after the low-fat meal. However, the TEM after the high-fat meal was significantly lower $(p<0.05)$ than after the low-fat meal. Correlation among thermoregulatory SNS activity and lipid metabolism

Figure 5 shows the relationship between thermoregulatory SNS activity and lipid metabolism. As shown in Fig. 5A, the VLF was significantly correlated $(r=0.56$, $p=0.002)$ with fat oxidation rate $\left(\mathrm{mg} \cdot \mathrm{min}^{-1}\right)$ in the

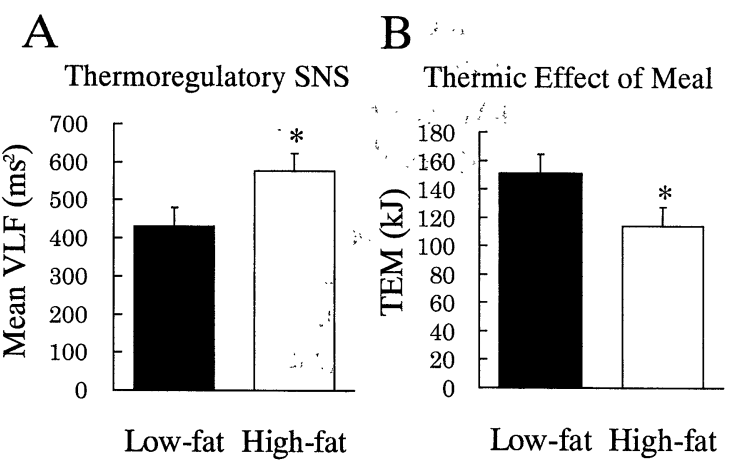

Fig. 4. (A) Postprandial VLF power (mean values, $\mathrm{ms}^{2}$ ) measured after a low-fat and a high-fat meal. (B) Thermic effect of meal (TEM) after a low-fat and a high-fat meal. The results are expressed as the mean \pm SE for each meal. ${ }^{* *} p<0.01,{ }^{*} p<0.05$, low-fat vs. high-fat meal.

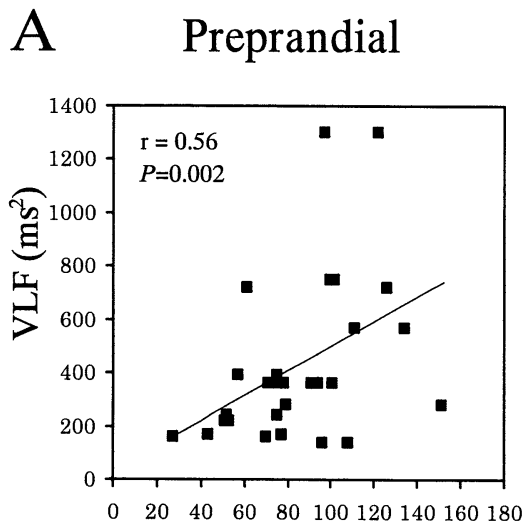

Fat oxidation (mg/min)

\section{B Postprandial}

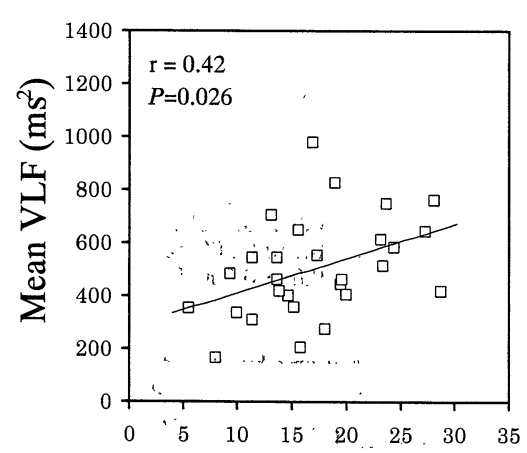

Fat oxidation $(\mathrm{g} / 3.5 \mathrm{~h})$

Fig. 5. (A) Relationship between preprandial Very-low frequency (VLF) power $\left(\mathrm{ms}^{2}\right)$ and fat oxidation $\mathrm{rate}\left(\mathrm{mg} \cdot \mathrm{min}^{-1}\right)$ before a low-fat and a high-fat test meal intake. (B) Relationship between postprandial VLF power (mean values, $\mathrm{ms}^{2}$ ) and total fat oxidation $(\mathrm{g})$ for $3.5 \mathrm{~h}$ after a low-fat and a high-fat meal. 
preprandial period. Similarly, the VLF (mean values) and total amount of fat oxidation $\left(\mathrm{g} \cdot 3.5 \mathrm{~h}^{-1}\right)$ was weakly, but significantly related $(r=0.42, p=0.026)$ in the postprandial period (Fig. 5B).

\section{DISCUSSION}

Our study revealed two major findings. Firstly, after a high-fat meal, thermoregulatory SNS activity assessed by measurement of the VLF of the HRV was significantly increased but the energy expenditure response was reduced compared with an iso-energetic low-fat meal. Secondly, thermoregulatory SNS activity may correlate with the amount of fat oxidation in the postprandial state. Elevated thermoregulatory SNS activity induced by the high-fat meal seems to be a part of the energy regulation system which burn excessive energy as heat production. In addition, a lower thermogenesis after the high-fat meal may be a consequence of limitations of lipid utilization, such as speed or efficiency of digestion, absorption, and $\beta$-oxidization processes.

Association of SNS and TEM responses following a high-fat meal

Regarding the association between the SNS activity and the TEM following the high-fat meal, Welle et al. (21) and Potter et al. (22) reported an increase of the SNS activity induced by plasma norepinephrine levels after the high-carbohydrate meal but not after the highfat meal (using $67 \mathrm{~mL}$ of corn oil or normal food items). Measuring the HRV, Tentolouris et al. (23) also found no significant increase in the SNS activity (LF/HF ratio) after the high-fat meal (using $100 \mathrm{~g}$ of walnuts). On the other hand, in agreement with our previous study (24), we found a rise in the SNS activity induced by the highfat meal, which might be associated with the level of fat oxidation. This discrepancy may be partly explained by the type of test meal and/or different methods of the SNS activity assessment procedures used in these studies. Since a clear association of increased thermoregulatory SNS activity (the VLF power) and higher amount of fat oxidation was shown, the new finding of this study may support the underlying mechanism of symptheticmediated lipolysis.

As for lipid metabolism and sympathetic involvement in human studies, a relationship between triglyceridefatty acid cycling and the SNS activity was suggested by Wolfe et al. (25), who used stable-isotope tracers and $\beta$ adrenergic blocking agents in patients with severe burns. Later, Stepniakowski et al. (26) found significant effects of lipid infusion on increased neurovascular tone. In addition, Paolisso et al. (4) recently demonstrated that lipid emulsion + heparin infusion was associated with a rise in plasma epinephrine and norepinephrine concentrations, and also an increase in the SNS activity evaluated by HRV power spectral analyses. Interestingly, after simultaneous propranolol infusion, a smoothed stimulatory effect on the cardiac ANS activity was observed, and the authors concluded that the effect of plasma fatty acids on the SNS is not only peripheral but is mediated, at least in part, by the central nervous system through increased plasma cate- cholamine concentrations (4). Similarly, the present data suggests that the VLF power of the HRV is associated with the rise in fat oxidation. Taken together, the aforementioned results $(4,22,23)$ and ours, show that increased thermoregulatory SNS activity may stimulate the extent of lipolysis. Moreover, our previous studies demonstrated that lower VLF responses to various sympathetic perturbations, such as cold exposure (12), capsaicin-containing diets (13), and liquid meals (14) were shown in obese women compared to lean young women. Accordingly, blunted sympathetic response to the high-fat meal may cause an attenuated lipid metabolism and consequently, future weight gain in the long run.

\section{High-fat meal and obesity}

A meta-analysis of dietary intervention studies have disclosed that a low-fat diet without a restriction of total energy intake results in not only a preventive effect on weight gain in normal weight subjects, but also a treatment effect among overweight individuals (27). In our present study, postprandial fat storage was about 10fold higher (39.5 \pm 9.4 vs. $4.0 \pm 5.2 \mathrm{~g}, p<0.001$ ) after the high-fat meal than after the low-fat meal. We therefore hypothesized that a high proportion of dietary fat, even within the normal daily range of calories, may increase fat storage over a long period of time. Although our data clearly demonstrated metabolic as well as sympathetic responses to the different fat contents of isoenergetic meals in men, we can not confirm our hypothesis due to the short-term nature of the experiment and limited number of subjects. Further studies are needed to clarify the involvement of insulin and leptin in the postprandial thermic and sympathetic responses after the test meals with various fat contents.

In summary, to examine a potential association between the high-fat meal and weight gain, we investigated postprandial thermogenesis as well as thermoregulatory SNS activity after low-fat and high-fat meals in healthy young men. The high-fat meal induced a significant increase in thermoregulatory SNS activity and a greater level of fat oxidation; however, a markedly lower TEM together with a positive fat balance was found after the high-fat meal compared to an iso-energetic low-fat meal, suggesting that a high proportion of dietary fat, even within the usual range for normal daily energy requirements, may be a potent risk factor for obesity over a long period of time.

\section{Acknowledgments}

This work was in part supported by a grant from the Rice Stable Supply Support Organization.

\section{REFERENCES}

1) Rothwell NJ, Stock MJ. 1979. A role for brown adipose tissue in diet-induced thermogenesis. Nature 281: 3135.

2) Rippe C, Berger K, Böiers C, Ricquier D, ErlansonAlbertsson C. 2000. Effect of high-fat diet, surrounding temperature, and enterostatin on uncoupling protein gene expression. Am J Physiol 279: E293-E300. 
3) Grekin RJ, Vollmer AP, Sider RS. 1995. Pressor effect of portal venous oleate infusion. A proposed mechanism for obesity hypertension. Hypertension 26: 195-198.

4) Paolisso G, Manzella D, Rizzo MR, Ragno E, Barbieri M, Varricchio G, Varricchio M. 2000. Elevated plasma fatty acid concentrations stimulate the cardiac autonomic nervous system in healthy subjects. Am J Clin Nutr 72: 723-730.

5) Tappy L. 1996. Thermic effect of food and sympathetic nervous system activity in humans. Reprod Nutr Dev 36: 391-397.

6) Abbott WGH, Haward BV, Christin L, Freymond D, Lillioja S, Boyce VL, Anderson TE, Bogardus C, Ravussin E. 1988. Short-term energy balance: relationship with protein, carbohydrate, and fat balances. Am J Physiol (Endocrinol Metab) 255: E332-337.

7) Maffeis C, Schutz Y, Grezzani A, Provera S, Piacentini G, Tato L. 2001. Meal-induced thermogenesis and obesity: is a fat meal a risk factor for fat gain in children? J Clin Endocrinol Metab 86: 214-219.

8) Yoshioka M, St-Pierre S, Suzuki M, Tremblay A. 1998. Effects of red pepper added to high-fat and high-carbohydrate meals on energy metabolism and substrate utilization in Japanese women. Br J Nutr 80: 503-510.

9) Akselrod S, Gordon D, Ubel FA, Shannon DC, Barger AC, Cohen RJ. 1981. Power spectrum analysis of heart rate fluctuation: a quantitative probe of beat-to-beat cardiovascular control. Science 213: 220-222.

10) Moritani T, Hayashi T, Shinohara M, Mimasa F, Shibata M. 1993. Comparison of sympatho-vagal function among diabetic patients, normal controls and endurance athletes by heart rate spectral analysis. J Sport Med Sci 7: 31-39.

11) Moritani T, Hayashi T, Shinohara M, Mimasa I, Masuda I, Nakao K. 1995. Sympatho-vagal activities of NIDDM patients during exercise as determined by heart rate spectral analysis. In: Glucose Fluxes, Exercise and Diabetes (Kawamori R, Vranic M, Horton ES, Kubota M, eds), p 91-96. Smith-Gordon, Great Britain.

12) Matsumoto T, Miyawaki T, Ue H, Zenji C, Moritani T. 1999. Autonomic responsiveness to acute cold exposure in obese and non-obese young women. Int J Obes Relat Metab Disord 23: 793-800.

13) Matsumoto T, Miyawaki T, Ue H, Yuasa T, Miyatsuji A, Moritani T. 2000. Effects of capsaicin-containing yellow curry sauce on sympathetic nervous system activity and diet-induced thermogenesis in lean and obese young women. J Nutr Sci Vitaminol 46: 309-315.

14) Matsumoto T, Miyawaki C, Ue T, Kanda T, Yoshitake Y, Moritani T. 2001. Comparison of thermogenic sympathetic response to food intake between obese and nonobese young women. Obes Res 9: 78-85.

15) Nagai N, Sakane N, Narukami H, Kugenuma H, Moritani T. 2003. The effect of pungent principle of spices on postprandial thermogenesis, satiety, and sympathetic nervous system activity in children. J Jpn Soc Study Obes 9: 156-163 (in Japanese).

16) Nagai N, Sakane N, Hamada T, Kimura T, Moritani T. 2005. The effect of a high-carbohydrate meal on postprandial thermogenesis and sympathetic nervous system activity in boys with a recent onset of obesity. Metabolism 54: 430-438.

17) Health, Labor and Welfare Ministry of Japan. 1999. Recommended Dietary Allowance for Japanese, 6th revision, p 36-39. Printing Beureau of Finance Ministry, Tokyo (in Japanese).

18) Resources Council, Ministry of Education, Culture, Sports, Science and Technology of Japan. 2001. The Japanese Food Composition Table, 5th revision. Daiichi Publishing, Tokyo (in Japanese).

19) Lusk G. 1924. Animal calorimetry: analysis of the oxidation of mixtures of carbohydrate and fat. J Biol Chem 59: $41-42$.

20) Rompelman O, Coenen AJR, Kitney RI. 1977. Measurement of heart-rate variability: Part 1-comparative study of heart rate variability analysis methods. Med Biol Eng Comput 15: 233-239.

21) Welle S, Lilavivat U, Campbell RG. 1981. Thermic effect of feeding in man: Increased plasma norepinephrine levels following glucose but not protein or fat consumption. Metabolism 30: 953-958.

22) Potter DHJF, Hartley G, Macdonald IA, James OFW. 1990. Blood pressure, heart rate and neuroendocrine responses to a high carbohydrate and a high fat meal in healthy young subjects. Clin Sci 79: 517-522.

23) Tentolouris N, Tsigos C, Perea D, Koukou E, Kyriaki D, Kitsou E, Daskas S, Daifotis Z, Makrilakis K, Raptis SA, Katsilambros N. 2003. Differential effects of high-fat and high-carbohydrate isoenergetic meals on cardiac autonomic nervous system activity in lean and obese women. Metabolism 52: 1426-1432.

24) Nagai N, Sakane N, Linda MU, Hamada T, Moritani T. 2003. The $-3826 \mathrm{~A} \rightarrow \mathrm{G}$ variant of the uncoupling protein-1 gene diminishes postprandial thermogenesis after a high-fat meal in healthy boys. J Clin Endocrinol Metab 88: $5661-5667$.

25) Wolfe RR, Herndon DN, Jahoor F, Miyoshi H, Wolfe M. 1987. Effect of severe burn injury on substrate cycling by glucose and fatty-acids. N Engl J Med 317: 403-408.

26) Stepniakowski KT, Goodfriend TL, Egan BM. 1995. Fatty acids enhance vascular $\alpha$-adrenergic sensitivity. Hypertension 25: 774-778.

27) Astrup A, Ryan L, Grunwald GK, Storgaard M, Saris W, Melanson E, Hill JO. 2000. The role of dietary fat in body fatness: evidence from a preliminary meta-analysis of ad libitum low-fat dietary intervention studies. $\mathrm{Br} J \mathrm{Nutr}$ 83: S25-S32. 